\title{
Impacto das Instituições Estaduais na Unidade das Coalizões Parlamentares no Brasil*
}

\author{
John M. Carey \\ Gina Yannitell Reinhardt
}

\section{INTRODUÇÃO}

C

omo as instituições afetam, se o fazem, a tendência de deputados de um partido ou coalizão a votarem unidos? Esta pergunta tem despertado a atenção dos estudiosos do Congresso norte-americano (Cox e McCubbins, 1993; Krehbiel, 1998; Wright e Schaffner, 2002). A maior facilidade de acesso a dados sobre votos de parlamentares fora dos Estados Unidos permitiu analisar esse tema em diferentes contextos institucionais (Figueiredo e Limongi, 2000; Hix, 2002; Carey, 2002). Neste artigo, utilizamos dados sobre votações realizadas na Câmara dos Deputados do Brasil, de 1989 a 1998, para analisar os efeitos de dois fatores institucionais que, de acordo com a teoria, influem na unidade de voto de grupos de deputados eleitos no mesmo distrito: a competição dentro da lista eleitoral e a aliança com governadores. Os dados brasileiros mostram que o aumento da competição dentro da lista enfraquece a unidade de voto e que a aliança com governadores não aumenta a unidade, podendo inclusive diminuí-la.

Muitos sistemas de representação proporcional com lista permitem aos eleitores ter algum controle sobre quem os representa, porque

\footnotetext{
* [A tradução do original em inglês "State-level Institutional Effects on Legislative Coalition Unity in Brazil" é de Vera Pereira.]

DADOS - Revista de Ciências Sociais, Rio de Janeiro, Vol. 46, n- 4, 2003, pp. 773 a 804.
} 
abrem a possibilidade de dar um voto preferencial a um candidato em uma lista de concorrentes. A representação proporcional de lista aberta - RPLA é uma variante muito comum, adotada no Brasil, Peru, Chile, Polônia, Finlândia e Sri Lanka. Neste sistema, todos os votos dados à lista de uma coligação eleitoral são primeiramente agregados para determinar sua proporção em relação ao total de cadeiras alocadas a um estado, mas dentro da lista a distribuição das vagas realiza-se de acordo com o número de votos preferenciais que cada candidato recebe. Assim, a reputação coletiva da coalizão tem grande valor para um candidato, porque influi no total de cadeiras que a coligação eleitoral conquista, mas também dá lugar à competição entre os candidatos da mesma aliança, o que os estimula a procurarem afirmar reputações individuais que os distingam dos seus companheiros de coalizão. Carey e Shugart (1995) alegam que, nesses sistemas, a importância relativa do indivíduo em face da reputação da coligação cresce à medida que aumenta o número de aliados da lista, os quais, é claro, também competem entre si.

O segundo fator institucional cuja influência na unidade de voto nos interessa analisar é a aliança com governadores. O impacto dos governos estaduais sobre as coalizões parlamentares vem se tornando cada vez mais relevante por causa da proliferação de reformas destinadas a descentralizar o poder político para os estados ou províncias em países tão diversos quanto a Índia, África do Sul, Argentina, Colômbia, Bolívia, Venezuela, Grã-Bretanha e Rússia. É comum defender-se a delegação de autoridade e de responsabilidades na formulação de políticas sob o argumento de que os governos estaduais ou provinciais são mais sensíveis às condições locais e mais eficientes do ponto de vista fiscal e regulador (Tiebout, 1956; Weingast, 1995; Montinola et alii, 1995). No entanto, a descentralização pode ter conseqüências imprevistas na formação e manutenção de coalizões políticas (Eaton, 2001; O'Neill, 1998; Treisman, 1999). As reformas descentralizadoras geralmente aumentam a independência eleitoral dos políticos estaduais com relação aos federais, facilitam o acesso dos primeiros às receitas públicas e aumentam suas responsabilidades na provisão de serviços básicos, o que, por sua vez, fortalece o poder de barganha e influência dos governantes estaduais em comparação com os políticos que atuam no âmbito federal (Willis et alii, 1999; Garman et alii, 2001). 
As pesquisas especializadas sobre o federalismo na América Latina ressaltam a importância dos governadores como construtores de coalizões parlamentares. Esse tipo de observação é muito conhecido no caso brasileiro, em que os governos estaduais há décadas controlam grandes somas de recursos e se acredita que os governadores têm grande influência na capacidade dos presidentes para cumprir sua agenda legislativa (Mainwaring, 1999; Samuels, 2000c; Montero, 2000). Argumentos semelhantes costumam ser levantados em relação a outros sistemas federativos da América Latina. Spiller e Tommasi (2000), por exemplo, afirmam que a descentralização do poder em benefício das províncias argentinas aumentou a influência dos governadores no futuro político dos deputados federais, fazendo com que a autoridade para estabelecer e fazer cumprir acordos parlamentares acabasse se deslocando, na prática, para fora do Congresso. No México, com o fim do longo predomínio do Partido Revolucionário Institucional - PRI, os observadores têm estado atentos a uma dinâmica semelhante (Ugalde, 2000; Garman et alii, 2001).

O Brasil é um sistema federativo em que os estados constituem, por si sós, distritos eleitorais nas eleições para o Legislativo. Os membros da Câmara dos Deputados são eleitos no sistema de RPLA por distritos que correspondem a estados inteiros. O tamanho das bancadas estaduais varia de um mínimo de oito representantes, nos estados de menor população, a um máximo de setenta, no caso do estado mais populoso, São Paulo. Isto quer dizer que a magnitude do distrito eleitoral varia de oito a setenta. As listas eleitorais podem ser compostas com candidatos de um só partido ou de uma coligação de partidos estaduais. A unidade de análise deste estudo é a coorte ou grupo de deputados que participam de uma coalizão estadual - o grupo de deputados eleitos na lista de um partido ou coligação formada em um estado brasileiro - durante determinada legislatura. Utilizamos dados referentes a três períodos legislativos: 1986-1991, 1991-1995 e 1995-1998. Referimo-nos, de modo geral, a coalizões, quer se trate de um só ou de muitos partidos, porque a unidade de competição eleitoral é a lista, que pode ser composta de candidatos de um ou de mais de um partido. Denominamos o grupo de deputados eleitos por uma dada coalizão em um determinado estado de coorte coligada [coalition cohort]. Calculamos o efeito dos dois fatores institucionais mencionados - tamanho da coorte e sua ligação com o governador de um estado - sobre a disciplina nas votações na Câmara dos Deputados. 
É importante assinalar que a coalizão é a unidade organizacional decisiva da política parlamentar brasileira, tanto no âmbito eleitoral quanto no do processo decisório (Figueiredo e Limongi, 2000; Amorim Neto, 2002). As eleições estaduais e nacionais no Brasil criam sistemas partidários fragmentados. Para formar maiorias governistas, presidentes e governadores articulam coalizões pluripartidárias e distribuem pastas ministeriais* entre os partidos aliados em troca de apoio. As coalizões são formadas inicialmente para a disputa eleitoral dos maiores troféus da política brasileira: o controle dos governos estaduais e da Presidência da República. As alianças pluripartidárias que apóiam candidatos a governadores elaboram chapas de candidatos para as assembléias estaduais e o Congresso Nacional, e os votos dados são agregados para a distribuição de cadeiras de tal modo que a vitória ou derrota de um pretendente a deputado está diretamente relacionada com a do candidato a governador que lidera sua coligação estadual.

$\mathrm{O}$ artigo desenrola-se da seguinte maneira. Primeiramente, fazemos uma resenha das pesquisas existentes sobre o papel das regras eleitorais e dos governadores nas coalizões parlamentares no Brasil. Baseados nessas pesquisas e em um modelo de influência dos governadores no voto disciplinado da coorte coligada, formulamos uma série de hipóteses para analisar dados relativos a votações realizadas na Câmara dos Deputados. Introduzimos, em seguida, um conjunto de índices para calcular a unidade de voto de qualquer coorte de deputados, quer seja designada por coalizão, partido, estado, região ou combinações destas características. Usamos esses índices para testar uma série de modelos que estimam os efeitos do tamanho da coorte e da aliança política com governadores no voto unido desses deputados. Apresentamos os resultados e concluímos com uma discussão sobre suas implicações e limitações, oferecendo orientações para futuras pesquisas.

\section{DETERMINANTES DO VOTO DO PARLAMENTAR: FATORES INSTITUCIONAIS}

\section{Competição Dentro da Coalizão e Tamanho da Coorte}

A lógica que nos permite supor que o tamanho da coorte influi no voto parlamentar disciplinado no sistema eleitoral brasileiro de

\footnotetext{
* [Ou secretarias de governo - N. do T. $]$
} 
RPLA deriva do modelo desenvolvido em Carey e Shugart (1995). Quando há somente um deputado eleito por uma coligação, as reputações do parlamentar e da aliança a que ele pertence são idênticas. Em uma coorte de dois deputados, o valor da reputação coletiva é dividido entre eles. Quando há um número maior de deputados em uma bancada, todos são competidores em potencial pelos votos dados à lista, e, portanto, cada um terá de tentar afirmar uma reputação individual no grupo de concorrentes a fim de se colocar entre os principais puxadores de voto da lista e ser premiado com uma das vagas conquistadas. O aumento do número de concorrentes também exacerba o problema relacionado com o mecanismo de agregação dos votos dados à lista, porque desestimula um candidato a abrir mão de oportunidades de acumular apoio pessoal em nome da preservação da reputação coletiva da coalizão (Ostrom, 1990).

Vale notar que, nos sistemas de RPLA, o efeito marginal do aumento do tamanho da coorte é o inverso do observado nos sistemas de representação proporcional de lista fechada - RPLF, nos quais os eleitores não dão votos preferenciais dentre os candidatos da lista, e a ordem de distribuição das vagas é previamente determinada pela posição que os candidatos ocupam na ordenação inicial da lista. No sistema de RPLF, quanto maior o tamanho da lista, mais anônimos são os candidatos. Como nesse sistema a importância de cada candidato é pequena, também são menores os incentivos para que ele procure afirmar uma reputação individual (Cain et alii, 1987; Carey e Shugart, 1995).

Resumindo: nossa hipótese é a de que nos sistemas eleitorais de RPLA - e, de modo geral, naqueles em que as regras estimulam a competição por votos preferenciais entre membros do mesmo partido e entre aliados em uma coligação - o voto indisciplinado nas coortes coligadas deve aumentar com o tamanho do grupo. Cox e Thies (2000) mostram dados que comprovam esta hipótese em um estudo sobre o financiamento de campanhas no Japão, onde, antes de 1994, o sistema eleitoral de voto único não transferível - SVNT incentivava a competição intrapartidária de modo semelhante ao que ocorre no sistema brasileiro de RPLA. Quanto maior o número de competidores entre correligionários de um partido, mais fundos de campanha os candidatos à Dieta japonesa levantavam e gastavam. Na opinião de Cox e Thies, a medida do individualismo parlamentar é muito mais o dinheiro do que o modo de votar, mas, no fundo, o que importa é o fato 
de a presença de um maior número de concorrentes em um mesmo partido estimular o comportamento individualista. Nossa medida será o modo de votar dos parlamentares, mas, por uma lógica análoga, supomos haver menos unidade de voto nas coortes com número maior de membros do que nas menores.

\section{Os Governadores: Construtores ou Destruidores de Coalizões?}

As pesquisas especializadas na política brasileira divergem quanto à extensão da influência dos governadores sobre os deputados federais e quanto a se esta influência estimula ou desestimula a unidade do partido. Os que enfatizam o poder dos governadores ressaltam, em primeiro lugar, a estrutura das carreiras políticas. Os governadores geralmente controlam a organização dos seus partidos, competindo a eles aprovar as candidaturas para os cargos legislativos. Os candidatos a governador são os árbitros da distribuição de indicações de nomes para as chapas que concorrem ao Congresso entre os vários partidos integrantes de suas alianças eleitorais. São eles também que controlam o acesso a recursos privados para as campanhas. Enfim, os governadores dominam as indicações para cargos estaduais, influem no destino dos projetos patrocinados por fundos federais, bem como nas decisões dos órgãos reguladores e licenciadores (Ames, 2001; Mainwaring, 1999; Samuels, 2000c; Weyland, 1996). Samuels (2000a; 2000b) demonstra que o sucesso dos governadores em eleger candidatos ao Congresso pertencentes às suas coalizões permite prever a possível influência que terão sobre esses deputados no período entre eleições:

"O sucesso dos governadores na eleição de candidatos dos seus partidos acaba enfraquecendo a capacidade do presidente da República de construir coalizões de governo. Quando os deputados eleitos chegam em Brasília para cumprir seus mandatos, têm de cuidar dos interesses dos governadores de seus estados de modo a não criar inimigos poderosos" (Samuels, 2000a).

Um estudo recente de Argelina C. Figueiredo e Fernando Limongi (2000) questiona a caracterização do comportamento em plenário dos deputados brasileiros como motivado essencialmente por interesses estaduais. Argumentam esses autores que a Constituição brasileira concede aos presidentes uma soma de recursos orçamentários e procedurais suficiente para lhes permitir controlar a agenda legislativa e 
"as verbas das quais depende a sobrevivência política dos parlamentares", isto é, a capacidade de influir nas políticas públicas e em seu uso patrimonialista (idem:152 e 165) ${ }^{1}$. Segundo esse raciocínio, o controle dos presidentes sobre a agenda legislativa significa que os deputados têm pouco a lucrar se opondo ao governo, mesmo que seus patronos estaduais prefiram esse comportamento, porque atos isolados de voto independente não afetam os resultados da política. Por outro lado, se os deputados optam por agir coletivamente, ganham uma chance de arrancar concessões do governo federal. Figueiredo e Limongi alegam que os partidos e coalizões nacionais são os meios pelos quais os deputados organizam a ação coletiva, e a obediência ao partido e às coalizões nacionais é o preço que até os políticos mais individualistas e localistas admitem pagar para aumentar seu poder de barganha na negociação com o governo federal.

Quem são os líderes nacionais com os quais os governadores competem pela influência sobre os deputados de suas coortes estaduais? Qualquer grupo de parlamentares que representem mais de $1 \%$ do total de membros da Câmara de Deputados no Brasil pode formar um bloco e eleger um líder e vice-líderes por maioria simples dos seus integrantes. Os blocos têm direito à representação na Mesa da Câmara, na proporção do número de seus membros, e a tomar parte em comissões (Regimento Interno, artigos 8, 10, 14, 15 e 23). Os líderes de blocos controlam as indicações de deputados para as comissões e o tempo de tribuna que usam, além de representarem seus membros na escolha da pauta e do cronograma legislativos (Figueiredo e Limongi, 2000:164-165). Portanto, se de um lado a participação em um bloco parlamentar federal proporciona recursos aos deputados, de outro os subordina aos líderes. Finalmente, no sistema partidário fragmentado do Brasil, as coalizões que incluem blocos são essenciais para a política parlamentar. Para garantir apoio parlamentar confiável, os presidentes brasileiros articulam coalizões distribuindo pastas ministeriais, como é praxe nos sistemas parlamentaristas (Amorim Neto, 2002).

As tentativas de comprovar empiricamente a influência dos governadores no voto dos deputados têm gerado resultados desiguais. Ames (2002) e Cheibub et alii (2002) examinam a hipótese de que governadores aliados a líderes nacionais incentivam a lealdade dos deputados aos líderes nacionais. Ames (2002) estuda a influência dos governadores sobre os deputados de seus próprios partidos, valendo-se do 
fato de que, na Câmara dos Deputados brasileira, os líderes ditam as orientações de voto em muitas decisões e determinam a posição oficial do partido nacional. Considerando a grande soma de recursos controlados pelos governadores, Ames sugere que "a cooperação [com os líderes] deveria ser maior quando um deputado representa o partido do governador". No entanto, a análise dos votos dos parlamentares não confirma tal hipótese, o que leva Ames (idem:211) a concluir que "os governadores não tinham uma influência constante sobre os deputados de seus estados". Utilizando dados sobre um maior número de votações, apesar de sobrepostas, Cheibub et alii (2002) não encontraram diferença alguma no apoio às proposições legislativas do governo federal entre deputados provenientes de estados nos quais o partido do governador participa do ministério de coalizão, em comparação com o comportamento dos deputados provenientes de estados em que o governador pertence a um partido de oposição ao presidente.

Desenvolvemos, neste artigo, um modelo alternativo sobre as relações entre governadores, líderes nacionais e deputados, o qual ilustra a capacidade dos governadores para reforçar ou enfraquecer a unidade de voto dos políticos sobre os quais exercem influência.

\section{Unidade Estadual em Votações Legislativas}

Nos lugares em que a eleição de políticos e a organização de coalizões se dão na esfera estadual, é possível supor que coortes pertencentes à mesma coalizão estadual votem unidas quando chegam ao Congresso. A Tabela 1 mostra a desagregação dos votos (em "sim" e "não") de grupos de deputados estaduais pertencentes a três coalizões (A, B e C) em um sistema hipotético formado por dois estados (X e Y). $A$ e $B$ mostram uma unidade perfeita entre as coortes coligadas. As duas coortes da coalizão $A$ votam da mesma maneira e esta unidade se transfere para o plano nacional. Os votos dos grupos de deputados da coalizão $B$, provenientes de diferentes estados, são conflitantes, provavelmente em relação a políticas públicas de alocação de recursos por regiões, acarretando a desunião da coalizão nacional. As coortes da coalizão $C$ também estão divididas internamente, o que também concorre para a desunião nacional. Portanto, a desunião no âmbito nacional poderia ser causada por divergências entre coortes coligadas, pela simples discórdia entre membros de coortes estaduais ou por uma combinação desses dois fatores. 
Impacto das Instituições Estaduais na Unidade das Coalizões...

Tabela 1

Desagregação dos Votos Dados por Deputados de uma Coalizão em uma Votação Hipotética em um Sistema Federativo

\begin{tabular}{l|c|c|c}
\hline \multirow{2}{*}{ Estados } & \multicolumn{3}{|c}{ Coalizões } \\
\cline { 2 - 4 } & A & B & C \\
\hline$X$ & $50-0$ & $50-0$ & $25-25$ \\
$Y$ & $50-0$ & $0-50$ & $25-25$ \\
\hline Total & $\mathbf{1 0 0 - 0}$ & $\mathbf{5 0 - 5 0}$ & $\mathbf{5 0 - 5 0}$ \\
\hline
\end{tabular}

O cenário postulado para a coalizão $B$, em que a unidade no âmbito nacional se encontra prejudicada pela adesão de coortes internamente divididas, baseia-se na hipótese de que algum tipo de força atuante no plano estadual une os deputados integrantes de determinadas bancadas. Uma explicação plausível poderia estar na existência de um interesse regional comum. Entre os fatores institucionais, deve-se levar em conta a existência de regras eleitorais que incentivam a unidade entre deputados eleitos na mesma lista (na RPLF, por exemplo) ou o controle sobre os governos estaduais, desde que o apoio dos governadores signifique que os deputados vão segui-lo. Isso levanta o problema de saber se fatores institucionais poderiam ajudar a explicar por que determinadas coortes se parecem mais com as que fazem parte das coalizões $A$ e $B$, na Tabela 1 , ou com as da coalizão $C$.

Nossa hipótese relativamente ao efeito do tamanho da coorte na unidade de voto é simples e clara: quanto maior o número de membros, menor é a unidade. Entretanto, no que se refere aos governadores, sugerimos que o efeito depende, em primeiro lugar, de que a influência do governador se some ou se oponha à pressão dos líderes nacionais e, em segundo lugar, da força relativa dos governadores e dos líderes nacionais sobre os deputados. Considere-se primeiramente um cenário em que o governador fecha com os líderes nacionais de todos os partidos que fazem parte de sua base aliada no estado ${ }^{2}$. Dado que a influência do governador apenas reforça a dos líderes nacionais, os grupos de deputados ligados ao governo do estado devem votar pelo menos tão unidos quanto aqueles que não têm vínculos com o governador. Quanto mais forte é a influência do governador, maior será a sua pressão para um comportamento disciplinado dos parlamentares que fazem parte de sua coalizão estadual. Essa relação positiva e uni- 
forme está expressa na curva dos "efeitos de reforço mútuo entre os mandantes ou principais" [reinforcing principals] da Figura 1.

Vejamos agora um cenário em que o governador diverge dos líderes nacionais dos partidos que compõem sua coalizão de governo. Os deputados aliados ao governador estarão submetidos a pressões contraditórias entre mandantes rivais - de um lado, seu governador, de outro, os líderes do seu partido no Congresso Nacional. Nessas circunstâncias, o efeito líquido da pressão do governador é mais complexo e dependerá da influência relativa dos governadores e dos líderes nacionais dos seus partidos. Se os governadores forem mais fracos que os líderes, não terão nenhum efeito líquido na unidade das coortes de sua coligação. Mas se a influência do governador crescer, o efeito líquido de sua pressão pela unidade da bancada estadual será negativo, conforme sugere a curva intitulada "efeitos da competição entre mandantes ou principais" da Figura 1, em que a unidade de voto dos

Figura 1

Dois Modelos sobre as Influências dos Governos Estaduais na Unidade de Voto das Bancadas de Partidos ou Coalizões Estaduais

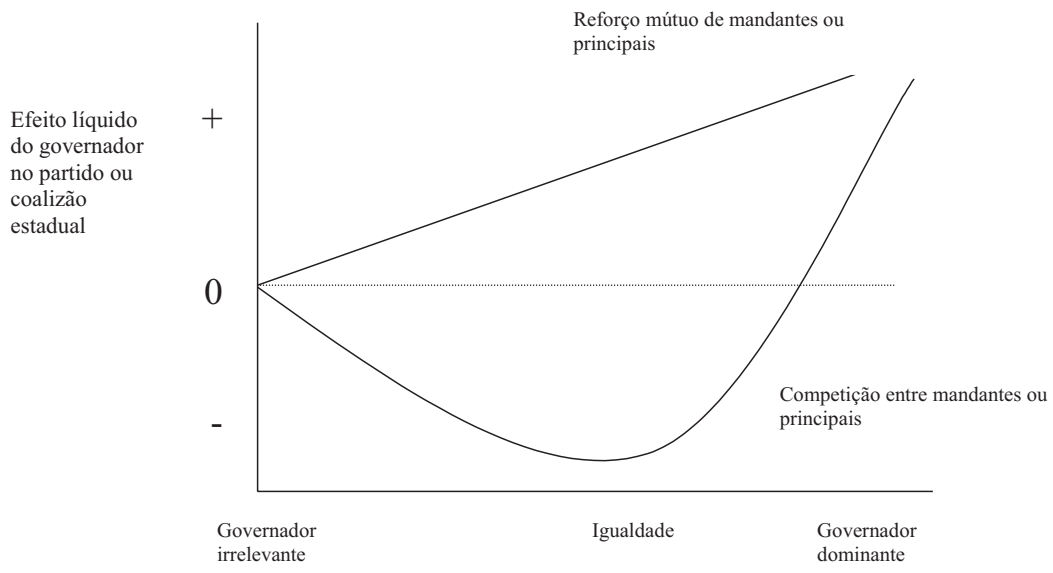

Influência relativa de governadores e líderes de partidos ou coalizões nacionais 
grupos de deputados ligados aos governadores pode ser inferior à dos grupos não submetidos a pressões cruzadas. Exemplificando, se o governador do Amazonas, cuja coalizão estadual inclui o Partido da Frente Liberal - PFL, Partido do Movimento Democrático Brasileiro - PMDB, Partido da Social Democracia Brasileira - PSDB e Partido Trabalhista Brasileiro-PTB, orienta sua bancada a fazer uma coisa e a liderança da coalizão governista de Brasília, que inclui os mesmos partidos, recomenda outra coisa, a conseqüência pode ser que a influência do governador semeie a desunião entre seus aliados parlamentares. Na medida em que a influência do governador vai além do ponto de paridade com a dos líderes nacionais (isto é, desloca-se para a direita na curva da Figura 1), o efeito negativo de uma aliança com ele poderia ser contrabalançado pela sua pura e simples dominação, ficando as coortes a ele ligadas perfeitamente disciplinadas - pelo menos mais do que os grupos não ligados ao governo estadual.

É evidente que os modelos de reforço mútuo e competição entre mandantes ou principais são simplificações. Na realidade, a atitude dos governadores em toda a gama de votações realizadas em qualquer legislatura fatalmente reflete uma combinação dos dois modelos. $\mathrm{Na}$ maioria dos sistemas, na maior parte do tempo, quase todos os governadores fecha com as posições da liderança nacional dos partidos e coalizões que lhes dão apoio político, de modo que sua influência é no mínimo um reforço para a união dos deputados eleitos por seu estado. Poder-se-ia esperar que, no saldo líquido, o efeito positivo do reforço mútuo supere o efeito potencialmente negativo da competição entre mandantes ou principais. Por outro lado, se o efeito líquido dos governadores na unidade da bancada for negativo, é sinal de que a competição entre mandantes é muito forte, mesmo que ocorra em circunstâncias pouco usuais. Hix (2002) sugere uma explicação análoga em sua pesquisa sobre votações nominais no Parlamento Europeu, em que os deputados respondem a dois mandantes - os partidos nacionais, que controlam suas candidaturas e as eleições, e os líderes dos partidos do Parlamento Europeu, que controlam o acesso aos recursos da instituição. Nesse caso, os partidos do Parlamento Europeu são análogos às coalizões nacionais no Brasil, enquanto os partidos nacionais, que atuam em cada país, são análogos aos governadores brasileiros. Hix descobriu que a melhor explicação para a desobediência individual dos deputados à disciplina partidária no Parlamento Europeu está na posição ideológica dos partidos nacionais, e 
não na postura ideológica de cada indivíduo (que a pesquisa mede), o que indica a influência das autoridades de cada país, que detêm o controle dos recursos eleitorais, na explicação do voto no Parlamento Europeu.

Por último, vale a pena fazer menção ao peso do reforço mútuo ou da competição entre mandantes na unidade da coalizão no plano nacional. Se os governadores reforçam as pressões dos líderes nacionais, o resultado não pode ser outro: o controle dos governos estaduais deve aumentar a unidade no âmbito nacional. Se os governadores competem com os líderes nacionais, o efeito há de ser o enfraquecimento da unidade nacional, salvo na eventualidade de uma condição muito estrita: que, na ausência de um efeito de reforço mútuo entre os mandantes, as coortes estaduais sejam internamente unidas e contraditórias entre si. Um exemplo disso está na situação das coortes da coalizão $B$, na Tabela 1. Se a adição de um outro governador destruísse a unidade interna da coorte de $B$, seja no estado $X$ ou no estado $Y$, mantidas constantes as demais condições, o resultado seria aumentar a unidade de $B$ (ou a atenuar sua extrema desunião) no plano nacional. Todavia, essa combinação nos parece pouco provável; supomos que, na maioria dos sistemas políticos, o impacto líquido do efeito da competição entre mandantes seja o enfraquecimento da unidade da coalizão nacional.

\section{HIPÓTESES}

A discussão acima apresentada sugere-nos as seguintes hipóteses sobre os efeitos da competição entre candidatos de uma mesma lista e da influência dos governadores nos grupos de deputados de uma coalizão estadual na Câmara de Deputados no Brasil:

H1: a unidade de voto deve diminuir com o aumento do número de deputados que formam a bancada.

H2: Em qualquer coalizão estadual, o controle do governador deve aumentar a unidade de voto entre os membros da coorte coligada no Congresso (efeito de reforço mútuo entre os mandantes).

H2 : Em qualquer coalizão estadual, o controle do governador pode diminuir a unidade de voto entre os membros da coorte coligada no Congresso (efeito da competição entre mandantes). 


\section{DADOS E CÁLCULOS}

\section{Escores de Unidade de Voto}

Propomos duas formas de medir a unidade do voto a plicáveis a qualquer grupo relevante de legisladores - membros do mesmo partido, coalizão, bancada estadual ou coorte de partido estadual, grupo étnico, gênero e semelhantes:

UNIDADE $_{i j}=\mid \operatorname{sim}_{i j}-\%$ não $_{i j} \mid$ para o grupo $i$ na votação $j$, em que as porcentagens são calculadas em frações da totalidade dos membros do grupo. UNIDADE pode variar de zero (nenhum dos membros vota, ou os votos "sim" igualam os votos "não") a um (todos os membros votam unidos); e

$\operatorname{RICE}_{\mathrm{ij}}=\mid \% \operatorname{sim}_{\mathrm{ij}}-\%$ não $\mathrm{i}_{\mathrm{ij}} \mid$ para o grupo $i$ na votação $j$, em que não são considerados os membros do grupo que não deram votos "sim" ou votos "não". Isto é, as proporções de votos favoráveis ou contrários baseiam-se apenas nos que votaram ou "sim" ou "não" e, portanto, totalizam um. O escore RICE* pode variar de zero (número igual dos que votaram "sim" e votaram "não") a um (todos os que votaram deram o mesmo voto).

Por exemplo, se de um grupo de 100 deputados 60 votaram no "sim", 20 no "não" e 20 não votaram, o escore do grupo no índice de UNIDADE vai ser $0,4(=0,6-0,2)$, enquanto o escore no índice de RICE será $0,5(=0,75-0,25)$, calculando-se a proporção de votos "sim" e de votos "não" somente a partir dos que deram votos, e não pelo tamanho do grupo. Os dois índices estão relacionados, mas UNIDADE é descontado de acordo com a proporção dos membros do grupo que dão um voto decisivo. Portanto, o índice UNIDADE exprime o potencial de influência na votação que um grupo mobiliza, enquanto o índice RICE somente mede a coesão entre os membros do grupo que votam. Os dois índices variam de zero (para um grupo que não mobiliza toda a sua influência ou se divide eqüitativamente entre votos favoráveis e votos contrários) a $u m$ (para um grupo bem mobilizado e unido).

\footnotetext{
* [O nome do indicador RICE provém do índice de Rice - N. do T.]
} 
O índice de RICE é muito usado em análises sobre votações parlamentares há quase um século, mas, por registrar apenas votos favoráveis ou contrários, não dá conta do não-voto, que inclui a abstenção declarada, as ausências ou simplesmente o fato de alguém não depositar um voto (Rice, 1925). As análises sobre votações em assembléias legislativas onde o não-voto é usual costumam enfatizar que essa atitude pode ser uma manifestação de divergência no grupo (Ames, 2002; Smith e Remington, 2001). Ao introduzirmos o índice UNIDADE, adotamos uma posição agnóstica relativamente à intenção por trás dos não-votos, mas uma interpretação inequívoca das suas conseqüências - isto é, a intenção de um deputado de discordar da posição da coalizão a que pertence pode levá-lo ou a votar contra o grupo ou a não votar. As duas atitudes prejudicam a mobilização da coalizão no plenário, mas do ponto de vista aritmético votar contra a bancada é mais prejudicial do que não votar. Os dois índices registram os votos contra a bancada, só que UNIDADE também registra os não-votos e distingue as duas ações de acordo com seu efeito aritmético sobre a mobilização da coalizão na votação.

\section{Índices Ponderados}

Nossas unidades de análise são as coortes coligadas. Calculamos os índices UNIDADE e RICE para cada coorte estadual coligada na Câmara dos Deputados durante três legislaturas: 1986-1991,1991-1995 e 1995-1998. Concretamente, baseamo-nos em 57 votações no período de 1989 a 1990, 167 votações de 1991 a 1995 e 451 votações de 1995 a 1998. As votações foram selecionadas pelo mesmo critério de identificação das decisões mais importantes descritos em Figueiredo e Limongi $(2000)^{3}$.

Para criar um índice único de coesão UNIDADE ou RICE, para cada coorte, em todas as votações realizadas em uma determinada Assembléia Legislativa, ponderamos o escore de cada coalizão em cada votação, de acordo com a margem de votos da decisão, isto é, se o resultado foi mais ou menos apertado ${ }^{4}$. Com isso, descontamos as votações consensuais ou por larga maioria, nas quais qualquer subgrupo de deputados é, por definição, muito unido e a mudança de voto de qualquer pessoa é com certeza irrelevante para o resultado final. A intuição que fundamenta essa solução metodológica é a de que quanto maior for a probabilidade de que a mudança de voto de um deputado seja crucial para o resultado, mais nos interessa o voto disciplinado 
em qualquer grupo. Os escores (em ambos os índices) para qualquer subgrupo de legislaturas foram corrigidos da seguinte forma para gerar um índice ponderado:

INDICADOR $_{i}=\sum$ ESCORE $_{i j}{ }^{*}$ VOTAÇÃO APERTADA $_{j} / \sum V_{\text {VOTAÇÃO }}$ APERTADA $_{j}$

onde

VOTAÇÃO APERTADA AP $_{j} 1-\left(1 /\right.$ LIMIAR $^{*}$ LIMIAR - \%sim l $)$

para a Câmara como um todo

na votação $j$.

\section{As Coortes Pequenas}

Os 27 estados brasileiros elegem entre oito e setenta deputados federais cada um, de acordo com o tamanho da população. Nas três legislaturas examinadas nesta pesquisa, 93 coligações estaduais elegeram coortes de mais de um deputado - e nestas a unidade de voto é uma questão muito importante ${ }^{5}$. O tamanho das coortes coligadas incluídas em nossa análise varia de dois a 57 deputados, com uma média de sete. Isto quer dizer que muitas coortes estudadas são bastante reduzidas, e, como se sabe, este fato tem implicações metodológicas especiais para nossos índices de unidade de voto. O ponto principal é que um grupo de poucos membros pode criar um viés nos índices de unidade de voto, sobrelevando o apoio à H1. Considerando a suposição plausível de que o tamanho da bancada está correlacionado com a probabilidade de controlar o governo do estado, poderia haver uma distorção da análise contra o apoio à hipótese do efeito de reforço mútuo entre mandantes (H2) e a favor da hipótese H2 . Essa distorção pode ser corrigida estatisticamente e tomamos providências para ajustar todos os índices usados neste estudo. A caracterização geral do problema e as medidas tomadas para corrigi-lo são discutidas no Apêndice.

\section{O Troca-Troca de Partidos}

No cálculo dos índices UNIDADE e RICE, a afiliação de um deputado a uma coalizão pode ser definida seja de acordo com o grupo com que ele se elegeu, seja de acordo com o grupo ao qual ele está presentemente filiado. A troca de partidos é muito comum no Brasil (Desposato, 2002a; Rother, 2002). Quando um deputado muda para outro par- 
tido pertencente à mesma coligação eleitoral, a troca não afeta a composição da aliança, mas algumas trocas são feitas fora da coalizão de origem, de modo que as identidades eleitorais e as filiações correntes não são necessariamente as mesmas.

Os dois métodos de identificação refletem diferentes concepções do significado da coalizão. O pertencimento a uma coligação eleitoral é a "marca" com a qual um grupo de deputados buscou atrair votos, e a capacidade do grupo para agir em consonância depois de eleito é um reflexo da integridade dessa marca. Quando um deputado muda de afiliação após a eleição, a nova marca reflete as pressões imediatas da nova coalizão a que ele aderiu, e se a mudança significou a adesão à coalizão do governador, também a pressão por este exercida.

Calculamos os índices UNIDADE e RICE segundo as afiliações eleitorais e de acordo com o partido em que estava o deputado na época de cada votação. Testamos modelos para explicar a unidade de voto das duas formas e comparamos os resultados.

\section{O MODELO DE UNIDADE DA COALIZÃO ESTADUAL}

Testamos dois grupos de modelos de unidade de voto entre coortes coligadas. Agregamos os dados relativos aos três períodos legislativos acerca dos quais dispomos de registros de votos dados (1986-1991, 1991-1995, 1995-1998)6. O modelo básico de mínimos quadrados ordinários é descrito abaixo.

Para cada bancada $i$, em cada estado $j$,

UNIDADE $_{\mathrm{ij}}\left(\right.$ ou RICE $\left.\mathrm{Rij}_{\mathrm{ij}}\right)=$ Constante Deputados $_{\mathrm{ij}}+$ Governador $_{\mathrm{ij}}$ onde

UNIDADE $_{\mathrm{ij}}\left(\mathrm{RICE}_{\mathrm{ij}}\right)$ é o índice ponderado dos escores de UNIDADE $\mathrm{E}_{\mathrm{ij}}$ $\left(\right.$ RICE $\left._{\mathrm{ij}}\right)$ para a coorte da coalizão estadual em dado período legislativo;

Deputados $_{\mathrm{ij}}$ é o número de legisladores eleitos pela coalizão $i$ do estado $j$;

Governador ${ }_{i j}$ é uma variável binária [dummy variable] que indica se a coalizão $i$ controlava o governo do estado $j$ durante aquele período legislativo. 
Testamos o modelo para quatro variáveis dependentes: os índices UNIDADE e RICE, calculados segundo as afiliações eleitorais dos deputados, e depois, novamente, os dois índices calculados de acordo com a afiliação dos deputados na época da votação. Em seguida, testamos um segundo grupo de modelos, idêntico ao primeiro só que incluindo a seguinte variável independente:

Coalizão ${ }_{2} \ldots$ : : uma série de variáveis binárias, uma para cada coalizão original (com exceção de uma coalizão omitida, que serve de base de comparação) que elegeu deputados para a Câmara.

O coeficiente de cada variável binária de coalizão nos modelos de efeitos fixos indica a diferença esperada na unidade de voto para um grupo de deputados pertencentes àquela coalizão específica, em comparação com uma coorte da coalizão de base. Ocorre que a base de comparação é formada por um grupo de deputados do Partido dos Trabalhadores $-\mathrm{PT}^{7}$. Assim, por exemplo, a Coalizão ${ }_{45}$ identifica a combinação dos partidos PMDB, PSDB, PFL e Partido Democrático Social-PDS, de modo que seu coeficiente indica a diferença de unidade de voto esperada entre um grupo de deputados da coalizão estadual formada pelo PMDB-PSDB-PFL-PDS em oposição a um grupo de deputados do PT. O objetivo dessas variáveis é controlar o nível genérico de unidade de voto associado a cada coalizão singular, a fim de separar o efeito marginal do tamanho da coorte e da aliança com um governador das diferenças intrínsecas gerais entre as coalizões.

Especialistas em política brasileira sugeriram que, além de nossas variáveis institucionais, outras diferenças entre os estados brasileiros poderiam influir sistematicamente no grau de unidade das coortes coligadas. Por exemplo, se a política é mais clientelista em estados rurais pobres, e deputados clientelistas tendem a buscar obstinadamente benefícios particularistas para seus estados (verbas orçamentárias, digamos assim), sem quaisquer pruridos ideológicos, então o clientelismo pode determinar o voto disciplinado devido a mecanismos distintos dos incentivos institucionais associados com nosso modelo. Esses estados podem ter uma população menos numerosa e eleger coortes pequenas para o Congresso, fato que a variável tamanho da coorte de nosso modelo provavelmente iria atribuir à ausência de competição dentro da lista e não ao clientelismo. Para examinar esses efeitos, repetimos todas as nossas análises usando certas variáveis para controlar o PIB per capita do estado, a taxa de analfabetismo e ambas 
combinadas. Nas duas variáveis, os coeficientes tendem a ser negativos (isto é, estados mais ricos, de população mais alfabetizada, tendem a ter coortes um pouco menos unidas), conforme esperado, mas não alcançam significação estatística em quase todas as especificações e não alteram as estimativas de nossas variáveis institucionais. Por esse motivo, não foram incluídos nos resultados expostos na Tabela 2 .

\section{RESULTADOS}

Os resultados estão apresentados na Tabela 2. Em todos os casos, a variável dependente é o índice UNIDADE ou RICE ponderado por coorte estadual. Os erros-padrão estão entre parênteses, e os valores $p$ vêm logo abaixo. Começando pelos modelos básicos, vemos que os coeficientes para as duas variáveis independentes são negativos em todas as especificações e alcançam níveis convencionais de significação naquelas em que estimamos a unidade de voto pelo índice UNIDADE. Veja-se a diferença esperada entre uma coorte de quatro membros sem vínculos com o governador e outra com dez membros aliada ao governo do estado. A diferença esperada no índice UNIDADE entre essas duas coortes gira em torno de $-0,10$ ou mais da metade de um desvio-padrão. O efeito dessas variáveis, além disso, é quase o mesmo, quer se trate do índice UNIDADE calculado de acordo com a afiliação eleitoral do deputado ou de acordo com sua afiliação na época da votação. Quando a unidade de voto é estimada pelo índice RICE, o coeficiente continua negativo, mas a precisão dos dados diminui.

De modo geral, os modelos básicos confirmam H1 e H2 , ou seja, a explicação pelo efeito da competição entre mandantes e da influência do governo em coortes estaduais coligadas. Os grupos com maior número de deputados e os que são aliados do governador do seu estado não votam tão unidos na Câmara quanto os menores e sem ligação com governos estaduais. Contudo, os modelos básicos incorrem em uma grave limitação porque tratam todas as coalizões da mesma maneira, embora haja boas razões para crer que elas são diferentes. Coalizões são constituídas por partidos - a rigor, muitas de nossas coalizões são formadas por um único partido -, e as pesquisas especializadas em política brasileira mostram que os partidos diferem muito no grau de coesão interna dos seus membros, na disposição e na capacidade dessas organizações de impor disciplina aos seus parlamenta- 
Tabela 2

Efeito do Tamanho da Coorte e da Aliança com o Governador na Unidade de Voto ${ }^{a}$

\begin{tabular}{|c|c|c|c|c|c|c|c|c|}
\hline & \multicolumn{4}{|c|}{ Modelos Básicos } & \multicolumn{4}{|c|}{ Modelos de Efeitos Fixos } \\
\hline & \multicolumn{2}{|c|}{$\begin{array}{l}\text { Afiliação partidária na época } \\
\text { da eleição }\end{array}$} & \multicolumn{2}{|c|}{$\begin{array}{l}\text { Afiliação partidária na época } \\
\text { da votação }\end{array}$} & \multicolumn{2}{|c|}{$\begin{array}{l}\text { Afiliação partidária na época } \\
\text { da eleição }\end{array}$} & \multicolumn{2}{|c|}{$\begin{array}{l}\text { Afiliação partidária na época } \\
\text { da votação }\end{array}$} \\
\hline & UNIDADE & RICE & UNIDADE & RICE & UNIDADE & RICE & UNIDADE & RICE \\
\hline Constante & $\begin{array}{c}682 \\
(, 024) \\
, 000 \\
\end{array}$ & $\begin{array}{c}, 779 \\
(, 024) \\
, 000 \\
\end{array}$ & $\begin{array}{c}, 677 \\
(, 023) \\
, 000 \\
\end{array}$ & $\begin{array}{c}, 712 \\
(, 031) \\
, 000 \\
\end{array}$ & $\begin{array}{c}, 790 \\
(, 165) \\
, 000 \\
\end{array}$ & $\begin{array}{c}, 781 \\
(, 148) \\
, 000 \\
\end{array}$ & $\begin{array}{c}1,001 \\
(, 141) \\
, 000 \\
\end{array}$ & $\begin{array}{c}1,000 \\
(, 210) \\
, 000 \\
\end{array}$ \\
\hline $\begin{array}{l}\text { Coalizão do } \\
\text { governador }\end{array}$ & $\begin{array}{c}-, 031^{*} \\
(, 017) \\
, 067 \\
\end{array}$ & $\begin{array}{c}-, 023 \\
(, 017) \\
, 181 \\
\end{array}$ & $\begin{array}{c}-, 032 * \\
(, 017) \\
, 067\end{array}$ & $\begin{array}{c}-, 031 \\
(, 024) \\
, 196 \\
\end{array}$ & $\begin{array}{c}-, 006 \\
(, 019) \\
, 742 \\
\end{array}$ & $\begin{array}{c}-, 002 \\
(, 017) \\
, 891 \\
\end{array}$ & $\begin{array}{c}-, 001 \\
(, 020) \\
, 966 \\
\end{array}$ & $\begin{array}{c}, 012 \\
(, 029) \\
, 692 \\
\end{array}$ \\
\hline $\begin{array}{l}\text { Número de } \\
\text { deputados da } \\
\text { coorte }\end{array}$ & $\begin{array}{c}-, 011^{* * *} \\
(, 003) \\
, 000\end{array}$ & $\begin{array}{c}-, 004 \\
(, 003) \\
, 115 \\
\end{array}$ & $\begin{array}{c}-, 010^{* * *} \\
(, 003) \\
, 003\end{array}$ & $\begin{array}{c}-, 006 \\
(, 004) \\
, 167 \\
\end{array}$ & $\begin{array}{c}-, 016^{* * *} \\
(, 004) \\
, 000 \\
\end{array}$ & $\begin{array}{c}-, 009^{* * *} \\
(, 003) \\
, 005 \\
\end{array}$ & $\begin{array}{c}-, 011^{* *} \\
(, 004) \\
, 011 \\
\end{array}$ & $\begin{array}{c}-, 005 \\
(, 006) \\
, 414 \\
\end{array}$ \\
\hline & & & & & \multicolumn{4}{|c|}{$\begin{array}{l}\text { As variáveis binárias que identificam o efeito fixo para uma só } \\
\text { coalizão não estão apresentadas }\end{array}$} \\
\hline $\mathrm{N}$ & 177 & 177 & 189 & 190 & 177 & 177 & 189 & 190 \\
\hline $\mathrm{R}^{2}$ ajustado & 106 & 019 & ,078 &, 014 & ,486 &, 562 & ,499 & ,353 \\
\hline
\end{tabular}

${ }^{a}$ As variáveis dependentes estão expressas em índices ponderados de UNIDADE e de RICE para coortes de coalizões estaduais na Câmara dos Deputados. ${ }^{*}$ sig. $>0,10 ;{ }^{* *}$ sig. $>0,05 ;{ }^{* * *}$ sig. $>0,01$. 
res, bem como no modo de articularem e sustentarem coalizões pluripartidárias (Mainwaring, 1999; Ames, 2001; Amorim Neto, 2002). Assim, vários fatores, além do número de membros de uma coorte e sua relação com o governador, podem determinar a tendência inerente a qualquer coalizão a votar de modo disciplinado. Se esses fatores se correlacionam com quaisquer dos elementos institucionais em que estamos interessados, então os modelos básicos serão suscetíveis a distorção causada pela variável omitida. Em termos concretos, se uma aliança formada pelo PT e o Partido Comunista do Brasil - PC do B é intrinsecamente disciplinada, mas suas coortes geralmente são pequenas e é raro que a aliança conquiste o governo de um estado, os coeficientes negativos obtidos nas variáveis Deputados e Governador podem estar simplesmente refletindo o fato de que coortes numerosas e atreladas aos seus governadores geralmente não pertencem à aliança PT-PC do B, em vez de se tratar de um efeito institucional em si.

As especificações dos efeitos fixos do modelo corrigem essa possibilidade. Não incluímos na Tabela 2 as variáveis binárias para coalizões, porque elas são muitas (92), mas é importante dizer que quase todas geraram coeficientes negativos, o que é compatível com a reputação do PT e com o que geralmente se sabe acerca dos partidos e das coalizões no Brasil - isto é, que as coortes exclusivamente petistas estão obrigatoriamente entre as mais disciplinadas em qualquer coalizão possível ${ }^{8}$. Os resultados dos efeitos fixos confirmam $\mathrm{H1}$, ou seja, que o aumento do número de deputados em uma coorte diminui a unidade de voto, mas o efeito negativo da aliança com o governador desaparece.

O coeficiente da variável Deputados é negativo em todas as especificações e também se mostra significativo quando usamos como variável dependente o índice RICE, calculado segundo a afiliação eleitoral do candidato. O coeficiente continua negativo, mas não significativo, quando calculamos RICE pela afiliação do deputado na época da votação. Cabe lembrar que os modelos de efeitos fixos mantêm constantes todas as características de cada coalizão específica, salvo para as que estão especificadas no modelo. Assim, uma interpretação sobre o coeficiente da variável Deputados na terceira coluna da direita da Tabela 2 seria a seguinte: "Considere-se duas coortes do PMDB, uma com cinco membros e outra com quinze; a segunda deve marcar 0,09 ponto a menos (metade do desvio-padrão) no índice RICE que a de cinco membros." 
Os coeficientes da variável Governador são negativos em todas as especificações, salvo a última, mas nenhum é significativamente diferente de zero. Isto leva a crer que o ônus do vínculo com o governador detectado pelo modelo-padrão decorreu de uma distorção causada pela variável omitida - isto é, porque os tipos de coalizões que geralmente conquistam o governo de um estado tendem a ser "de baixa unidade", para começo de conversa. Controladas as características inerentes a cada coalizão por meio do modelo de efeitos fixos, não detectamos nenhum outro efeito significativo na unidade de voto relacionado com o fato de dominar um governo de estado?.

\section{DISCUSSÃO}

Os resultados dos testes estatísticos apóiam H1, isto é, a hipótese de que as coortes grandes são menos unidas que as pequenas. Os modelos de efeitos fixos mostram que isso ocorre mesmo quando se mantém constante a composição partidária das coortes. Esse resultado apóia a proposição de que no sistema de RPLA a competição entre membros da mesma coorte para afirmar uma reputação individual aumenta de acordo com o tamanho do grupo e pode debilitar a ação coletiva de coalizões parlamentares. Visto que o tamanho das coortes aumenta com a magnitude do distrito, pode-se pensar que o efeito do sistema de RPLA - e de outras regras que estimulam a competição por votos preferenciais entre candidatos de uma mesma coligação eleitoral - na unidade será particularmente intenso nos sistemas que têm distritos de grande magnitude (Carey e Shugart, 1995).

Não encontramos nenhuma comprovação para a explicação do reforço entre mandantes no que diz respeito à influência dos governadores no comportamento dos deputados - nenhuma "ajuda" do governador - em quaisquer especificações do nosso modelo. O modelo de efeito fixo também não evidencia a existência de um ônus devido à aliança com o governador, o que não corrobora a hipótese de um efeito da competição entre mandantes na influência do Executivo estadual, embora não se deva eliminar completamente essa hipótese apenas por esse resultado. Uma outra forma de interpretar a Tabela 1 explica por quê. A hipótese de haver um efeito da competição entre mandantes supõe uma relação não-monotônica entre o poder dos governadores (relativamente ao dos líderes da coalizão nacional) e o efeito de controlar o governo de um estado sobre a unidade de voto de uma coorte de deputados. Se o modelo descreve corretamente os go- 
vernadores como rivais em potencial dos líderes nacionais na disputa pela lealdade dos parlamentares, a pressão sobre a unidade da coorte deveria aumentar com o peso da influência do governador até um determinado ponto, mas em seguida regredir para perto de zero à medida que cresce o poder dos governadores, ou até mesmo deslocar-se para um segmento positivo no caso de governadores muito influentes.

Por essa razão, o coeficiente da variável Governador que é indistinguível de zero não fornece evidências claras sobre o efeito da competição entre mandantes. Não se deve, porém, eliminar de todo a possibilidade de que alguns governadores caiam no segmento $a$ da curva de competição entre mandantes, onde seu efeito líquido sobre a unidade da coorte é próximo de zero. Isto é coerente com a idéia de que os governadores brasileiros exercem uma influência considerável, mas não predominante, sobre os deputados federais, e que eles disputam esse poder com os líderes da coalizão nacional - uma interpretação que vai ao encontro da ênfase de Figueiredo e Limongi (2000) na importância dos partidos e coalizões nacionais brasileiros para a construção de alianças parlamentares e da importância que Samuels (2000a; 2000b; 2000c), Ames (2001) e Mainwaring (1999) atribuem ao efeito complicador das pressões estaduais sobre a ação coletiva no Congresso.

Alguns episódios respaldam essa interpretação da política brasileira. Um exemplo notório foi o ajuste de contas amplamente divulgado entre o presidente Fernando Henrique Cardoso e o ex-presidente Itamar Franco, em 1998-1999. Fernando Henrique, do PSDB, foi eleito para um segundo mandato presidencial em outubro de 1998. Na mesma eleição, Itamar Franco, do PMDB, o maior partido do Congresso naquela ocasião, elegeu-se governador de Minas Gerais. No plano nacional, o PMDB fizera parte da coalizão pluripartidária que apoiou Fernando Henrique; o partido endossou tacitamente a candidatura de Fernando Henrique, não concorrendo com candidato próprio à eleição presidencial, nem apoiando quaisquer dos seus adversários. Também participou do gabinete ministerial do primeiro governo de FHC (1994-1998) e continuou a fazê-lo no segundo mandato do presidente (1998-2003).

Logo após a eleição de 1998, FHC enviou ao Congresso um conjunto de leis que cortava aposentadorias e a folha de salários dos governos 
estaduais, e cobrava dos estados o pagamento de dívidas vencidas com o governo federal. O governador Itamar Franco declarou-se veementemente contrário ao pacote de medidas, convocou os deputados de Minas Gerais a votarem contra o plano e tentou reunir outros governadores em um cartel de estados devedores. Comentando o fato, o cientista político Cláudio Gonçalves Couto observou que, "levando em conta o poder que os governadores têm sobre suas bancadas no Congresso, pode-se dizer com toda segurança que Fernando Henrique vai se chocar contra uma muralha de resistência" às suas propostas (Latin America Data Base - LADB on-line, 30/10/1998).

Fernando Henrique contra-atacou nas duas frentes, a federal e a estadual. Primeiro, fez lembrar aos deputados dos partidos da coalizão governista, sem qualquer subterfúgio, seu dever de apoiar a agenda legislativa do governo, declarando: "Espero que os partidos que apóiam o governo realmente o apóiem e a maneira de apoiá-lo é votando a favor no Congresso". Além disso, advertiu os membros do seu Ministério de que sua permanência nos cargos dependia diretamente do apoio dos seus partidos no Congresso (LADB, 15/1/1999). Depois, sem atender ao pedido de perdão da dívida do estado feito por Itamar Franco, Fernando Henrique ofereceu a outros governadores uma série de concessões menores. Itamar, enquanto isso, reuniu-se com os líderes do seu partido no Congresso, em uma tentativa de convencê-los a apoiar sua atitude (LADB, 5/3/1999).

Fernando Henrique venceu a batalha legislativa imediata: os outros governadores aceitaram suas concessões, não se formou nenhum cartel de devedores e o PMDB continuou no Ministério. De uma perspectiva mais geral, porém, o conflito impôs alguns ônus ao presidente. $\mathrm{O}$ Estado de Minas Gerais declarou moratória de sua dívida, o que contribuiu para a crise monetária de 1999 e a subseqüente recessão da economia brasileira.

Apesar da ambigüidade dos resultados de nossas estatísticas acerca da influência dos governadores na unidade de grupos de deputados, a hipótese sobre o efeito da competição entre mandantes se mantém plausível e autoriza uma análise mais detalhada. Para fazer uma análise mais sistemática dessa relação, é necessário contar com dados que possibilitem medir diferenças de poder entre os governadores, para verificar se uma influência mais forte realmente gera o efeito não-linear presumido sobre a unidade de voto dos deputados. Isto é, 
nos estados onde os governadores são fracos, em comparação com o partido nacional e os líderes da coalizão, um aumento da força do governo local deve ampliar a distância entre as coortes estaduais e exacerbar o efeito negativo da aliança com o Executivo estadual na unidade de voto. Nos estados em que os governadores são mais fortes, um aumento de seu poder possivelmente estreitará a distância entre as coortes que têm e não têm ligações com eles, o que reduz o ônus decorrente de tais ligações. Por fim, nos estados em que os governadores têm um domínio quase total sobre os deputados estaduais, em comparação com os líderes nacionais, a distância deve novamente ampliar-se, mas o efeito líquido pode ser positivo.

O passo decisivo, portanto, é identificar uma variável que diferencie os governadores de acordo com seu poder sobre os deputados aliados e incluí-la como variável independente na avaliação da unidade da coorte. O indicador do poder do governador deve refletir seu controle sobre recursos que os deputados consideram muito importantes e até quando eles acreditam que esse controle deverá persistir. Infelizmente, durante quase todo o período coberto por nossos dados, os governadores estavam proibidos de concorrer a uma reeleição sucessiva, de modo que, constitucionalmente, eram carta fora do baralho para fins eleitorais, o que torna suspeita qualquer avaliação quantitativa acerca do seu futuro domínio sobre recursos políticos. A proibição constitucional foi suspensa em fins de 1997, permitindo-se uma reeleição sucessiva. Assim, depois de 1998, é possível distinguir entre os governadores de primeiro mandato, reelegíveis mais uma vez, e os de segundo mandato, que não podem concorrer na eleição seguinte. Dessa forma, os dados sobre votações no Congresso posteriores a essa data permitirão medir com exatidão o efeito do poder do governador na unidade da sua bancada estadual, abrindo-se um caminho promissor para futuras pesquisas.

Resumindo: há grande polêmica entre os especialistas em política comparada sobre os efeitos das instituições no comportamento dos políticos. Identificamos dois fatores institucionais que possivelmente afetam a unidade de coalizões parlamentares - o tamanho das bancadas e os vínculos com governadores - e medimos seu impacto no sistema federativo brasileiro, em que as eleições seguem as regras da RPLA e se realizam em distritos que abrangem todo o estado. Nessas condições, ambos os fatores têm suficiente variação para nos permitir calcular seus efeitos na unidade de coortes estaduais coligadas. A 
análise das informações sobre votos dados em votações realizadas na Câmara dos Deputados, de 1989 a 1998, confirma a proposição de que as coortes grandes são menos unidas do que as pequenas sob regras eleitorais que estimulam a competição entre aliados da mesma coalizão. Não encontramos nenhum efeito líquido da aliança com governadores sobre a unidade de voto entre grupos de deputados da coalizão estadual na Câmara dos Deputados. Este resultado exclui a pertinência da explicação da influência dos governadores por um efeito de reforço mútuo entre mandantes, mas não nos permite chegar a uma conclusão definitiva sobre a hipótese oposta, a do efeito da competição entre mandantes. A análise levou-nos, porém, a vislumbrar uma estratégia alternativa para futuras pesquisas sobre esse tema.

(Recebido para publicação em dezembro de 2002)

(Versão definitiva em maio de 2003)

\section{NOTAS}

1. A base empírica de nossa argumentação é a mesma que usamos neste artigo. Figueiredo e Limongi forneceram-nos sua base de dados sobre votações realizadas na Câmara dos Deputados.

2. Se as coalizões estaduais e nacionais sempre fossem formadas pelos mesmos partidos, o problema estaria apenas em saber se a posição do governo se harmonizava com a da coalizão no plano nacional. Só que, no Brasil, as alianças estaduais muitas vezes não refletem as que se estabelecem no âmbito federal, de modo que é necessário examinar especificamente os efeitos da influência dos governadores em suas coalizões estaduais.

3. Figueiredo e Limongi nos cederam generosamente sua base de dados original.

4. É importante observar que na maioria das assembléias algumas votações não são decididas por maioria simples dos votantes. Os dois principais desvios da maioria simples se dão quando o quórum para a aprovação de projetos de lei é estabelecido em termos absolutos (isto é, como porcentagem do total de membros da assembléia e não do número de votantes), e quando a aprovação exige o apoio de uma maioria extraordinária (por exemplo, 3/5, $2 / 3$ etc.). A fórmula de ponderação das votações leva em conta esses fatores, de modo que definimos uma votação apertada como aquela em que a mudança de voto de um parlamentar é decisiva e não como aquela em que a soma dos votos "sim" empata com a soma dos votos "não" (Carey, 2002).

5. Algumas dessas coalizões eram específicas para determinada legislatura, mas muitas elegeram coortes em mais de um estado e/ou período legislativo. Assim, 


\section{John M. Carey e Gina Yannitell Reinhardt}

em nossas análises estatísticas, o número de observações é superior a 93. A bem dizer, a variação dentro do grupo entre as coalizões é proporcional ao peso estatístico para as análises dos efeitos fixos.

6. Os modelos usados para examinar o Congresso de 1986-1990 não incluem os estados de Roraima, Amapá e Tocantins, que só foram criados pela Assembléia Constituinte de 1987 / 88 e, portanto, não realizaram eleições para governador em 1986. Também excluímos do período o Distrito Federal, porque Nicolau (1998) não tem os resultados para o governo do estado. Utilizamos modelos que incluem variáveis binárias específicas para cada período, a fim de determinar se mudanças ocorridas no tempo afetam os resultados. No segundo período legislativo, a unidade foi inferior à do primeiro período, e no terceiro foi maior, mas essas especificações não alteram os resultados substantivos ou os efeitos estatísticos de nossas variáveis institucionais.

7. É preciso lembrar que nossas unidades de análise - as coalizões - podem constituir-se de um só ou de muitos partidos. As coalizões omitidas para a análise dos modelos de efeitos fixos representam, portanto, uma coorte de deputados do PT que não se aliou a nenhum outro partido.

8. A íntegra dos resultados pode ser solicitada aos autores.

9. Vale notar, nesse sentido, que mesmo se não corrigíssemos os índices para evitar o viés devido ao pequeno tamanho do grupo, o efeito negativo ou o ônus da aliança com o governador se revelaria até nos modelos de efeitos fixos. A razão disso é que as coortes pequenas, para as quais o viés negativo é mais grave, geralmente não têm vínculos com os governadores. Agradecemos a Scott Desposato por nos ter alertado energicamente para o problema da distorção causada pelos grupos pequenos, bem como por incentivar todos os pesquisadores que estudam índices de unidade de voto a prestarem rigorosa atenção às questões metodológicas levantadas em Desposato (2002b). 


\section{REFERÊNCIAS BIBLIOGRÁFICAS}

AMES, Barry. (2001), The Deadlock of Democracy in Brazil: Interests, Identities, and Institutions in Comparative Politics. Ann Arbor, University of Michigan Press. (Publicado em português como Os Entraves da Democracia no Brasil, Rio de Janeiro, Fundação Getulio Vargas Editora, 2003.)

. (2002), "Party Discipline in Brazil's Chamber of Deputies", in S. Morgenstern e B. Nacif (orgs.), Legislative Politics in Latin America. New York, Cambridge University Press, pp. 185-221.

AMORIM NETO, Octavio. (2002), "Presidential Cabinets, Electoral Cycles and Coalition Discipline in Brazil", in S. Morgenstern e B. Nacif (orgs.), Legislative Politics in Latin America. New York, Cambridge University Press, pp. 48-78.

CAIN, Bruce, FEREJOHN, John e FIORINA, Morris. (1987), The Personal Vote: Constituency Service and Electoral. Cambridge, MA, Harvard University Press.

CAREY, John M. (2002), “Party Unity in Legislative Voting”. Working Paper, no 376, Department of Political Science/Washington University.

e SHUGART, Matthew S. (1995), “Incentives to Cultivate a Personal Vote: A Rank Ordering of Electoral Formulas". Electoral Studies, vol. 14, no 4, pp. 417-439.

CHEIBUB, José Antonio, FIGUEIREDO, Argelina Cheibub e LIMONGI, Fernando. (2002), Presidential Agenda Power and Decision-Making in Presidential Regimes: Governors and Political Parties in the Brazilian Congress. Trabalho apresentado na American Political Science Association - APSA.

COX, Gary W. e MCCUBBINS, Mathew D. (1993), Legislative Leviathan: Party Government in the House. Berkeley, University of California Press.

COX, Gary W. e THIES, Michael F. (2000), “How Much Does Money Matter? 'Buying' Votes in Japan, 1967-1990". Comparative Political Studies, vol. 33, no 1, pp. 37-57.

DESPOSATO, Scott. (2002a), "Parties for Rent? Ambition, Ideology, and Party-Switching in Brazil's Chamber of Deputies". Working Paper, University of Arizona.

. (2002b), "Correcting for Bias in Roll Call Cohesion Scores". Working Paper, University of Arizona.

EATON, Kent. (2001), “Decentralisation, Democratization, and Liberalisation: The History of Revenue Sharing in Argentina, 1934-1999". Journal of Latin American Studies, $\mathrm{n}$ - 33, pp. 1-28.

FIGUEIREDO, Argelina Cheibub e LIMONGI, Fernando. (2000), "Presidential Power, Legislative Organization, and Party Behavior in Brazil". Comparative Politics, vol. 32, n- 2, pp. 151-170.

GARMAN, Christopher, HAGGARD, Stephan e WILLIS, Eliza. (2001), "Fiscal Decentralization: A Political Theory with Latin American Cases". World Politics, vol. 53, no 2 , pp. 205-236. 


\section{John M. Carey e Gina Yannitell Reinhardt}

HIX, Simon. (2002), "Parliamentary Behavior with Two Principals: Preferences, Parties, and Voting in the European Parliament". American Journal of Political Science, vol. 46, n- 3, pp. 688-698.

KREHBIEL, Keith. (1998), Information and Legislative Organization. Ann Arbor, University of Michigan Press.

LATIN AMERICAN DATA BASE - LADB. (1998), “Brazil: President Fernando Henrique Cardoso Unveils Economic Plan Following Regional Elections". Notisur - Latin American Affairs, vol. 8, no - 40, 30 de outubro.

. (1999). “Brazil: New Financial Crisis Hits as President Fernando Henrique Cardoso Begins Second Term". Notisur - Latin American Affairs, vol. 9, nํ2, 15 de janeiro.

. (1999), “Brazil: Economic Volatility Continues Despite Successes by President Fernando Henrique Cardoso". Notisur - Latin American Affairs, vol. 9, no 9, 5 de março.

MAINWARING, Scott P. (1999), Rethinking Party Systems in the Third Wave of Democratization: The Case of Brazil. Stanford, CA, Stanford University Press. (Publicado em português como Sistemas Partidários em Novas Democracias: O Caso do Brasil, Rio de Janeiro, Fundação Getulio Vargas Editora, 2001.)

MONTERO, Alfred P. (2000), “Devolving Democracy? Political Decentralization and the New Brazilian Federalism", in P. R. Kingstone e T. J. Power (eds.), Democratic Brazil: Actors, Institutions, and Processes. Pittsburgh, University of Pittsburgh Press.

MONTINOLA, Gabriela, QIAN, Yingyi e WEINGAST, Barry R. (1995), “Federalism, Chinese Style: The Political Basis for Economic Success in China". World Politics, $\mathrm{n}$ 은 48 , pp. $50-81$.

NICOLAU, Jairo Marconi. (1998), Dados Eleitorais do Brasil (1982-1996). Rio de Janeiro, IUPERJ/Revan.

O'NEILL, Kathleen. (1998), Explaining the Great Power Give-Away: Decentralization in the Andes. Trabalho apresentado nas conferências da APSA e LASA.

OSTROM, Elinor. (1990), Governing the Commons: The Evolution of Institutions for Collective Action. New York, Cambridge University Press.

RICE, Stuart A. (1925), “The Behavior of Legislative Groups". Political Science Quarterly, n은 40, pp. 60-72.

ROTHER, Larry. (2002), "Long Treated as a Joke. Brazilian Neofascist May Have the Last Laugh". New York Times on-line, 16 de outubro. Disponível em <http:/ / www.nytimes.com/2002/10/21/international/americas/21BRAZ.html>.

SAMUELS, David J. (2000a), “The Gubernatorial Coattails Effect: Federalism and Congressional Elections in Brazil". The Journal of Politics, vol. 62, nํ1, pp. 240-253.

. (2000b), “Concurrent Elections, Discordant Results: Presidentialism, Federalism, and Governance in Brazil". Comparative Politics, vol. 33, n- 1, pp. 1-20.

. (2000c), "Ambition and Competition: Explaining Legislative Turnover in Brazil". Legislative Studies Quarterly, vol. 25, n을, pp. 481-497. 
SMITH, Steven S. e REMINGTON, Thomas F. (2001), The Politics of Institutional Choice: The Formation of the Russian State Duma. Princeton, NJ, Princeton University Press.

SPILLER, Pablo T. e TOMMASI, Mariano. (2000), “The Institutional Foundations of Public Policy: A Transactions Approach with Application to Argentina". Working Paper, Universidad de San Andres, Buenos Aires.

TIEBOUT, Charles. (1956), "A Pure Theory of Local Expenditures". Journal of Political Economy, vol. 64, nํㅜ 5 .

TREISMAN, Daniel. (1999), "Political Decentralization and Economic Reform: A Game-Theoretic Analysis". American Journal of Political Science, vol. 43, no 2, pp. 488-517.

UGALDE, Luis Carlos. (2000), The Mexican Congress: Old Player, New Power. Washington, Center for Strategic and International Studies.

WEINGAST, Barry. (1995), “The Economic Role of Political Institutions: Federalism, Markets, and Economic Development". Journal of Law, Economics, and Organization, vol. 11, no 1 , pp. 1-31.

WEYLAND, Kurt. (1996), Democracy without Equity: Failures of Reform in Brazil. Pittsburgh, University of Pittsburgh Press.

WILLIS, Eliza, GARMAN, Christopher e HAGGARD, Stephan. (1999), “The Politics of Decentralization in Latin America". Latin American Research Review, vol. 34, no 1, pp. 7-56.

WRIGHT, Gerald C. e SCHAFFNER, Benjamin F. (2002), “The Influence of Party: Evidence from the State Legislatures". American Political Science Review, vol. 96, nํㅡ, pp. 367-379. 


\section{APÊNDICE CÁLCULO DA UNIDADE DE VOTO EM GRUPOS PEQUENOS}

Há duas limitações importantes no cálculo da unidade de voto em grupos pequenos. A primeira é que o escore obtido no índice RICE não é relevante para grupos de um só membro $(\mathrm{N}=1)$, porque, por definição, é impossível votar contra a posição de companheiros inexistentes. Assim, não calculamos o índice RICE para coortes de um só integrante, nem para votações de que só um membro da coorte participou.

A segunda é que os índices UNIDADE e RICE são suscetíveis a um viés para mais como resultado da combinação do tamanho do grupo e da tendência subjacente de seus membros a votarem unidos (Desposato, 2002b). Essa distorção é tão mais grave quanto menor é o tamanho do grupo e menos propensos são os seus membros a votarem do mesmo modo. O problema é que a probabilidade de observar casos de alta unidade partidária (isto é, em que todos votam "sim" ou votam "não") é maior quanto mais grossas forem as caudas da distribuição binominal da proporção de votos "iguais". As medidas dessas caudas refletem valores mais elevados nos índices RICE e UNIDADE do que poderia sugerir a probabilidade subjacente de votar do mesmo modo, produzindo uma sobrelevação dos valores. As caudas das distribuições são mais grossas quando $\mathrm{N}$ é menor, e o viés resultante é mais pronunciado quando a probabilidade subjacente do voto unido também é menor. (Imagine-se a probabilidade de sempre dar "cara" unidade perfeita - quando se lançam duas moedas em comparação com lançar dez moedas.) A magnitude do viés do grupo pequeno diminui rapidamente à medida que aumentam o tamanho e a coesão do partido.

A análise de Desposato (2002b) sugere que o viés potencial dos escores de coesão pode ser corrigido estimando-se fatores desviantes no índice RICE, que são funções do tamanho do grupo e da tendência subjacente dos seus integrantes de votar unidos, e depois subtraindo esse fator do escore de RICE.

Adotamos nesta pesquisa o processo descrito abaixo. Calculamos para qualquer coalizão $i$, na votação $j$, a proporção de deputados que votaram do mesmo modo (T), acompanhando a maioria do grupo ou que deram um voto dissidente (D): 
- $\mathrm{T}_{\mathrm{ij}}$ = máximo [SIM, NÃO], em porcentagens dos votantes;

- $\mathrm{D}_{\mathrm{ij}}=$ mínimo [SIM, NÃO], em porcentagens dos votantes.

Pode-se calcular também proporções análogas de deputados mobilizados (M), os que são contra (O) e os que não votam (NV) com base no tamanho do grupo, em vez de somente considerar os que efetivamente votam:

- $\mathrm{M}_{\mathrm{ij}}$ = máximo [SIM, NÃO], proporcionalmente ao total de deputados;

- $\mathrm{O}_{\mathrm{ij}}=$ mínimo [SIM, NÃO], proporcionalmente ao total de deputados;

- $\mathrm{NV}_{\mathrm{ij}}=1-\mathrm{M}_{\mathrm{ij}}-\mathrm{O}_{\mathrm{ij} .}$

O escore de RICE é justamente $\mathrm{T}_{\mathrm{ij}}$ - $\mathrm{D}_{\mathrm{ij}}$ e o de UNIDADE é $\mathrm{M}_{\mathrm{i}}-\mathrm{O}_{\mathrm{i}}$. Os índices RICE e UNIDADE correspondentes são as somas de $T_{i}-D_{i}$ e $M_{i}$ - $\mathrm{O}_{\mathrm{i}}$ em todas as votações. Portanto, os índices refletem estimativas das probabilidades subjacentes de votar "contra" o grupo ou de não revelar ao grupo o voto dado.

Calculamos para cada coorte coligada $i$, o viés para mais esperado em decorrência do pequeno tamanho do partido da seguinte forma:

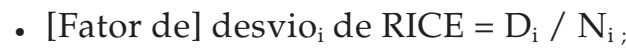

- $\left[\right.$ Fator de] desvio ${ }_{\mathrm{i}}$ de UNIDADE $=\mathrm{O}_{\mathrm{i}} / \mathrm{N}_{\mathrm{i}}$,

onde $\mathrm{N}_{\mathrm{i}}$ é o número de membros da coorte. Calculamos depois os índices "empiricamente corrigidos" para cada grupo de deputados subtraindo seu fator de desvio do índice "bruto". Os índices são "empiricamente corrigidos", porque os cálculos das probabilidades subjacentes de $\mathrm{D}_{\mathrm{i}}$ e $\mathrm{O}_{\mathrm{i}}$ se baseiam em dados de comportamento em plenário em todas as votações. $O$ fator de desvio cresce à medida que a probabilidade de votar contra o grupo aumenta, e diminui quando $\mathrm{N}_{\mathrm{i}}$ cresce. Para simplificar a exposição, não incluímos a palavra "corrigido" toda vez que nos referimos aos índices ajustados, mas todos os índices apresentados neste artigo foram corrigidos para eliminar a possibilidade de distorção. 


\section{ABSTRACT}

State-level Institutional Effects on Legislative Coalition Unity in Brazil

Research on political institutions suggests that sub-national factors affect the proclivity of legislators from the same party or coalition to vote together. We estimate the effects of such forces operating at the State-level - intra-list electoral competition, and alliance with governors. We propose that larger cohorts, in which the imperative for legislators to distinguish themselves from the group is stronger, should be less unified than smaller cohorts. We also derive from theoretical hypotheses that cohorts allied with governors may be either more or less unified than other cohorts. We analyze unity among coalition cohorts on recorded floor votes in the Brazilian Chamber of Deputies. We find support for the hypothesis that larger cohorts are less unified, but detect no net effect of alliance with governors on cohort voting unity. Governors are not dominant brokers of legislative coalitions, suggesting that the net gubernatorial effect is contingent on factors that shape their influence relative to national-level legislative actors.

Key words: legislatures; voting; governors; electoral rules; coalitions

\section{RÉSUMÉ}

L'Impact des Institutions des États Brésiliens sur l'Unité des Coalitions Parlementaires

Les recherches sur les institutions politiques indiquent que les facteurs sous-nationaux influencent la propension des législateurs d'un même parti ou coalition à voter unis. On analyse, dans cet article, les effets des forces institutionnelles agissant à l'échelon fédéral - la compétition électorale entre candidats d'une même liste et l'alliance avec des gouverneurs. On voit que les grandes cohortes, où le législateur éprouve le besoin de se démarquer du groupe, sont moins unies que les petites. En accord avec l'approche théorique, on voit aussi que les cohortes ayant une alliance avec les gouverneurs peuvent être plus ou moins unies que les autres cohortes. Cette analyse de l'unité entre des cohortes de coalition a pour base les votations dans la Chambre des députés brésilienne. On y voit donc confirmée l'hypothèse selon laquelle les grandes cohortes sont moins unies, mais on ne trouve aucun effet net de l'alliance avec des gouverneurs sur le vote uni des cohortes. Les gouverneurs ne sont pas des déclencheurs de coalitions parlementaires, ce qui laisse supposer que leur influence dépend de facteurs contingents façonnant leur pouvoir sur des acteurs politiques au niveau fédéral.

Mots-clé: législatures; vote; gouverneurs; règles électorales; coalitions 